\title{
Social and Cognitive Determinants in Participating in a Collaborative Platform
}

\author{
https://doi.org/10.3991/ijet.v14i19.10529 \\ Joanne M. Roch ${ }^{(凶)}$, Jean-François Roussel \\ Université de Sherbrooke, Québec, Canada \\ Joanne.roch@usherbrooke.ca
}

\begin{abstract}
If collaborative tools and platforms facilitate collaboration in principle, they do not do so every time. While organizations invest significantly in implementing collaborative tools, employees often prefer using communication channels they have developed and not those recommended by the organization.

After presenting various investigations describing the issues related to participating in virtual communities of practice, we present an example of implementing this innovative practice in an academic context. We began by putting into place a pilot project with a view to conducting a preliminary quantitative analysis taking into account facilitation strategies as the determining variable in participation and success. Quantitative data revealed that face-to-face interventions appear to have had an impact on participation, although not apparently lasting. A second qualitative analysis based on participant interviews reveals the importance of the concept of perceived usefulness, which has a significant impact on participation. Specifically, we were able to identify the importance of involving participants in designing this type of collaborative space. The study also reveals that account most be of how potential users assess the cost-effectiveness of investing in the proposed tool instead of the known available alternatives.

Our study highlights the social and cognitive dimensions related to participating in collaborative platforms and more precisely describe the factors that encourage or discourage participation.
\end{abstract}

Keywords-Virtual collaborative platform, pedagogical experience, participation, leadership

\section{Participation: A Core Dimension of Virtual Communities of Practice}

Whether in a teaching or workplace context, sharing information is an everbroadening practice for developing skills. In fact, according to Ref. [1], 78\% of Canadian organizations have implemented online collaboration, representing a $59 \%$ increase since 2008. If collaborative tools and platforms facilitate collaboration in principle, they do not do so every time (Ref. [2]). While organizations invest significantly 
in implementing collaborative tools, employees sometimes prefer using communication channels they have developed and not those recommended by the organization.

We therefore considered it relevant to attempt to gain a better understanding of the factors stimulating the engagement of the Players engaged in these new forms of collaboration founded on communication technologies. So, our research question aimed at identifying the variables driving or impeding the development of collaborative practices.

The first component of our research aimed at better understanding the determinants of online participation, more specifically, the impacts of leadership. We used Google Stats to measure the experiment's vitality, and correlated participation data to leadership interventions, whether in person or online. The second component focused on using semi-structured interviews to better understand the factors driving or impeding participation.

\subsection{Level of participation}

As stated in Ref. [3] participation is considered to be the foundation of the process of community construction and learning. According to Ref. [3], communities of practice are considered to be a type of learning community, whether virtual or not. They are characterized by three interrelated dimensions: mutual engagement, joint enterprise, and a shared repertoire. They have various categories of participants, including the core group, active participants, and occasional participants.

Ref. [3] pointed out that, on entering a community, an individual's participation could be rather peripheral before becoming more significant, depending on the level of member involvement and experience. The members of a community do not initially participate actively since they do not know how to act and thus gravitate to the periphery. In time, however, their observations and experience allow them to develop an understanding of how the community functions. Then, they become more active and can even serve as core members.

Participation takes into account all the virtual actions of learners and goes back to an individual's visible and identifiable engagement in the community of practice. Researchers have attempted to develop ways to account for different aspects of online interaction in communities of practice. An early attempt was proposed by Ref. [4] who assessed the level of student participation in a pedagogical experiment by counting the total number of messages published and posts made. Ref. [5] took into account, not only member actions such as sending messages or downloading documents, but also the lack of action. Three levels of participation intensity were therefore identified: active, passive, and inactive (discontinuity).

\subsection{Social and cognitive triggers of participation}

A virtual community can be described as a group of members of a professional or social network who share a common goal. Communication is primarily through electronic correspondence rather than face-to-face. The lack of social presence and contacts can negatively affect the establishment of interpersonal relations that stimulate 
the level of communication (Ref. [6]). Since the dominant mode of communication is written, strategies that attenuate the low level of social presence (leadership, face-toface encounters, etc.) must be identified.

In addition to the impact of the social component, Ref. [7] have brought out the importance of the cognitive component to the functioning of a virtual community of practice. Drawing on the model proposed by Ref. [8], the TAM (technology acceptance model) indicates that the user acceptance of computer use rests on two variables, in particular, namely, perceived usefulness (PU) and perceived ease of use (PEOU). Ref. [8] defined usefulness (U) as the degree to which a person believes that using a particular application or computer system would enhance their job performance. Ease of use (EOU) can be defined as the degree to which a user believes that a particular application or system would be easy to use. Figure 1 illustrates the conceptual diagram proposed by Ref. [8].

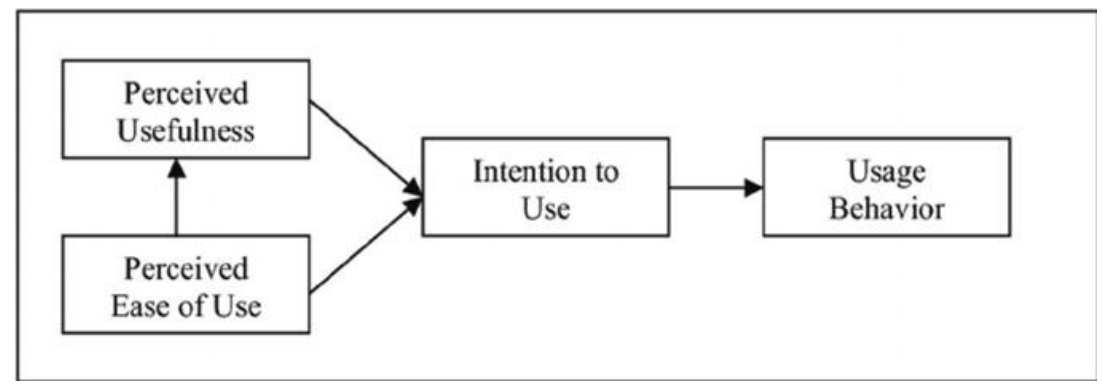

Fig. 1. TAM (Ref. [8])

In order to adequately adapt the model to the reality of virtual communities means extending the model in Ref. [8] to include the variable of social influence as introduced by Ref. [9] and revisited by Ref. [10]. Our model takes up the four stimulation drivers proposed in Ref. [10]: offline interaction (social presence), usefulness, IT infrastructure quality, and leader involvement, foundation on which leadership strategies rest.

Figure 2 presents the integrative model used in analyzing factors that contribute to stimulate players engaged in these new forms of collaboration founded on communication technologies. 


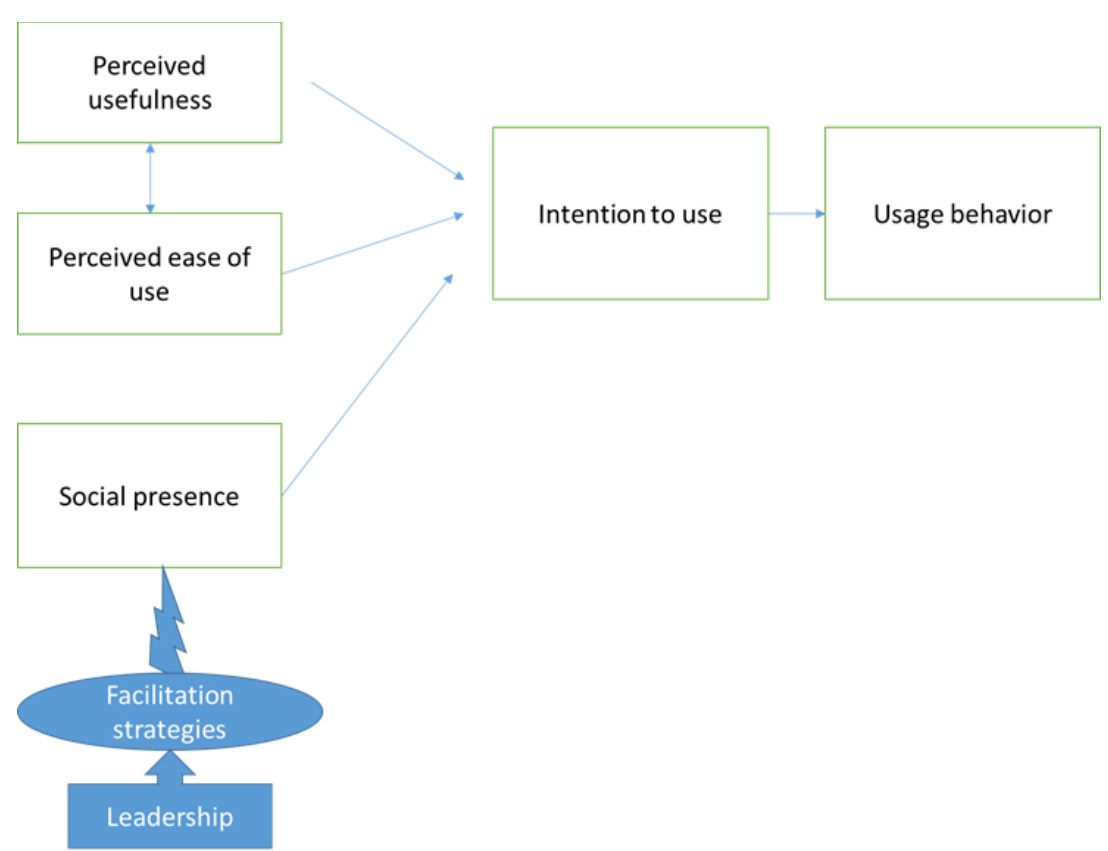

Fig. 2. Model of the determinants in participating in virtual communities (adapted from Ref. [8], Ref. [9], and Ref. [10])

The impacts of the social and the cognitive components on the functioning of a virtual community of practice are specified hereafter.

Social Component: The Importance of Leadership as a Trigger of Participation: Researchers (Ref. [11]) underscored the importance of putting into place a leadership team to stimulate and sustain the community of practice. It was also asserted that leaders act simultaneously on communication, motivation, leadership, and technological application in virtual communities (Ref. [12]). It was underscored that the lack of social connection weakens communication and the vitality of discussions, and that the fact that members are physically scattered represents a challenge to participation. In this regard, in order to be sustainable, a leader must stimulate virtual communities until they are able to share the leadership among themselves.

It was recommended (Ref. [13] and Ref. [12]) that organizations designate at least one leader mandated to motivate community members through their leadership, facilitation, mentoring, and administrative roles.

As a result, although a correlation between leader activities (online or face-to-face) and member participation in the virtual community has been demonstrated (Ref. [3]); little research has focused on describing the type of activities that stimulate participation (Ref. [14]). To encourage collaboration, Ref. [15] proposed without, however, specifying how to achieve this objective. For their part, Ref. [14] identified ways in which leaders can intervene, but deal only with virtual interventions (synchronous or asynchronous). 
Cognitive Component: The Importance of Perceived Usefulness: PU and PEOU are the two key constructs in TAM. The model theorizes PU and PEOU to determine intention and use behavior with respect to technology. Perceived usefulness is the degree to which an individual believes that using a particular system could enhance their workplace performance (analysis in terms of self-efficacy based on expected outcome and perceived consequences). Moreover, $\mathrm{PU}$ is high in a system when users perceived that system to be able to aid in acquiring raises, rewards, and promotion (Ref. [16]).

Perceived ease of use corresponds to the degree to which an individual believes that using a system would not involve much effort (analysis in terms of costs/benefits or motivations/impediments). As stated in Ref. [17], of these two variables, perceived usefulness is the determinant variable because, in their opinion, the technology variable (PEOU) would hardly come into play if perceived usefulness were high. In other words, there is a strong correlation between use and anticipated performance.

\section{Experiment: Implementing the Platform}

In existence for more than 20 years, the master's program in training management has more than 300 graduates and 85 active students working in the field of training and development in organizational settings. This master's degree covers the entire process of training management, both with respect to learning and management. The idea of setting up a collaborative platform was based on three main objectives, as described below.

- Necessity of Increasing Flexibility in the Training Offering: The students enrolled in the program are young professionals engaged in a development process who need flexibility because they must often reconcile family life and part-time education.

- Need to Promote Continuity in the Educational Experience: The University of Sherbrooke offers its students access to the Moodle platform, which is a digital tool provided first to educators in managing their courses. A typical cycle consists in first creating the site and then deregistering students from the site at the end of each course. The idea behind implementing a collaborative platform was to foster continuity within the master's program in training management.

- Possibility for Students to Reuse the Platform in Their Work Context: Moodle is, above all, an environment that facilitates the publication of course-related sites; little use is made of it by organizations in Quebec. A collaborative platform provides students with continuity in the learning experience and enables them to transfer it to their work environments.

\subsection{Main characteristics of the platform}

We were looking for a platform that would allow students to collaborate from anywhere and at any time in pursuing their learning project. More specifically, the plat- 
form had to provide for drafting academic documents collaboratively, sharing practices, improving group cohesion, and creating a relevant database continuously accessible throughout the entire master-degree pathway.

The collaborative-platform project put forward for the cohorts in the master of training management also had to allow learners to try out this approach in "incubator" mode so that they could subsequently assess the advantages and disadvantages of possibly implementing it in their organizations. Accordingly, we had to give preference to a platform that could be used in the organizational settings where our students worked.

We opted for the technology offered by Google and its Google Sites application because they made it possible to rapidly create collaboration sites and constituted an effective springboard for students who wanted to try out this type of digital space for the first time. In addition, it was flexible while remaining user-friendliness. The proposed platform included the following functionalities: page creation and modification; posting of shared documents, video clips, and images; space for creating discussion groups; space reserved for a news feed; and space dedicated to hosting online help. Appendix A presents the collaborative platform's template.

\section{Experiment Results}

\subsection{Value of mixed approaches in research}

Our study opted for a mixed methodology combining qualitative and quantitative data and methods in a single study (Ref. [18]). Our objective was not only to assess the effect of leadership on participation but also to understand the dynamics involved. Therefore, it was a sequential concept in which one type of research was followed by another to shed more light on what was found in the first part. The qualitative data generally expanded on and fleshed out the initial quantitative results. We consider that this type of design yields greater and more in-depth understanding of complex organizational phenomena.

\subsection{Component quantitative: Impact of leadership on participation}

In order to develop the four dimensions characterizing sustainable virtual communities (Ref. [19]); we implemented face-to-face leadership and coordination activities from the outset of the project (Ref. [11]). Moreover, we collected participation data that were automatically calculated by the software environment (Google Stats). In order to measure the experiment's vitality (Ref. [20]), we correlated the participation data to leadership interventions whether in person or online.

Face-to-face activities in a virtual training context are often viewed as a means for stimulating participation. Figure 3 provides the participation data for the collaborative platform in relationship to the face-to-face interventions. 


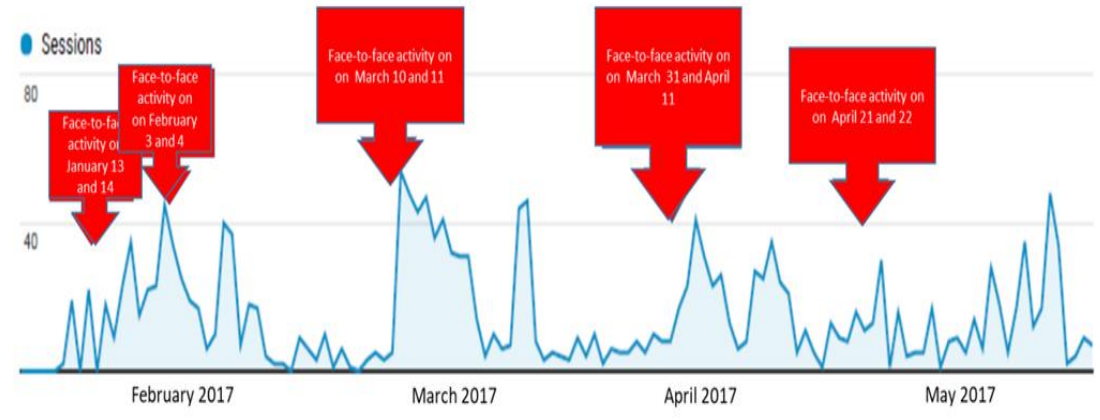

Fig. 3. Participation trends

These data reveal that the data for face-to-face interventions appear to have had an impact on participation, although it doesn't appear to have continued over time. There was an upswing in participation following a face-to-face activity, but the level of activity wasn't maintained afterwards.

These data could lead us to conclude that face to face meeting had a certain impact on the participation of the virtual community under study. The impact was however not maintained in time-similar to what pointed out in Ref. [3] — is not only driven externally and must, at a certain point, result from member activity. The face-to-face sessions, seem to have contributed to create temporarily a context conducive to the emergence of participation and student appropriation of the platform. In order to better understand the determinants motivating participation, we considered that a qualitative component was needed.

\subsection{Qualitative component: Better understanding participation motivation}

In order to better understand what triggered students' participation in the virtual collaborative platform, we opted for a qualitative approach to gain a deeper understanding of participant perceptions. The semi-structured interview was chosen for collecting data about participant experiences and to attempt to draw out a shared understanding (Ref. [21]). The interview included questions related to the main theoretical elements of the research as well as more general questions to bring out some elements that had not been identified previously.

We proceeded by inviting all students registered in the training management program (16 students) to take part in the research. Eight of the 16 students were interviewed by the researchers; the interviews lasted approximately 60 minutes. The recorded interviews were conducted starting in late August 2007 and subsequently transcribed and coded using QDA Miner software. The transcribed interview segments were coded using an open categorization based on emerging themes.

Analysis Results for the Qualitative Component: The results of this research are presented according to 2 major aspects. The first aimed at qualifying the participants' 
overall experience and their use of the platform. The second aimed at better understanding the factors that promoted or inhibited their participation.

Overall Experience: The majority of participants stated that they hadn't used the platform frequently or on a sustained basis. Some stated they only used it once. Most indicated that, although it was announced during courses and with regular reminders, they didn't use it on a sustained basis.

"I have the impression that once the lecturer presented it to us that activity on the platform increased; people said that we should use it. But that didn't last... It's as if, all of a sudden, people used the platform but not afterwards."

"We tried taking part in the beginning because it was new. I tried using it more when the lecturer when the lecturer came back in January to point out that we weren't using it very much. Then use dropped off completely."

The comments indicate that initial use was higher (curiosity factor) and then dropped off. Comments corroborates participation graphic presented Figure 3 that reflects increase in participation following face-to-face meetings with lecturer (facilitation strategies) followed by a decrease in participation afterwards.

They also reported that they felt a certain amount of social pressure to use the platform, primarily from the people who implemented it. This pressure wasn't strong enough, however, to result in sustained use. In fact, it appeared to have the opposite effect.

"Yes, one time, the lecturer came into our class...and that increased activity on the platform and people were telling themselves that we should be using it. But that didn't last long...you want to help her out, you want it to work well. So, there is an emotional load. On the other hand, she can be pretty adamant."

"The lecturer came and told us 'You're not using it but you have to.' We know that it's important for her and she found it quite useful...she really believes in its advantages. ...Clearly, being required to use it isn't going to make me use it. The opposite, actually, unless it's for credit. But, even then, I don't see the relevance."

Driving Forces: The participants brought out that some elements boosted their participation, in particular, the fact that the platform was, in some way, the gateway to other applications they used, such as such as their personal university e-mail account and Moodle, which hosts the sites for their courses and their student records.

"I would say that I used it really for the links to Moodle, e-mail, my student record, etc. That was about all. There were a few group interactions but hardly anything at all."

"In fact...it was because it is like a page that, most of all, gave us access to Moodle and our e-mail accounts. I always use it because the page opens automatically in my browser. Other than that, it serves for contacts that were already shared. Other than that, I didn't make much use of it."

"...All the links are together on the same page (e-mail, notes, fees). It's in my bookmarks. That's what I use and nothing else...The university's sites have a silo structure."

Impeding Forces -perceived usefulness: Among the impediments, the perceived usefulness remained the most significant variable. The majority of participants expressed that platform did not meet a specific need on their part. 
"Since it didn't really meet a need, I didn't see any reason to learn how to modify it. The result was that we didn't really buy into it."

"...currently, my work doesn't involve this need. I don't believe that I'm going to have this need on the short term. I have prioritized my time and things are moving quickly. With university, family, full-time work...I don't have an unlimited amount of time. That didn't leave any room for self-directed professional development."

Importance of Taking Part in the Platform's Initial Development: The students pointed out that they would have been more inclined to use the platform had they been involved in its design.

"In my opinion, if we had been involved in creating the platform, it would have attracted more interest. ...Maybe a new analysis and then building something based on needs. So, analyze needs and involve participants."

"It doesn't come from us and it's imposed on us...maybe we don't feel the need. Maybe if we had been involved from the outset in creating the platform. Now, anyone could modify it."

"Try to see what might be a need and then respond to the different options. Work together, so that the need is integrated and so that we want to take part. It's not that the cohort members aren't close, because we are very close. We see each other outside of class and do all kinds of things together. So, that's not the case. We're close. It would have been better if the stakeholders and group had built the platform together. That would have let people state their needs, their desires and see how that could be implemented."

The perceived usefulness was also directly affected by the presence of alternatives that students were already used to and preferred. Many comments indicated that the participants would prefer having other types of platforms and virtual discussion forums like those they currently use."

"Since we started doing our assignments as a team, that meant Hangouts, text messaging, or e-mail but not the platform. Someone posted about a cocktail event, but no one responded. We don't use it for assignments. We use Hangouts and text messages."

"Basically, whether for work or daily life, we use many communication platforms. That may be why we don't use it. I use Google Drive...Dropbox a lot. Moodle, too."

"To make it natural, there was no choice but to enhance its performance, make it more competitive with respect to the tools used. For example, Google Drive can be used to allow several people to modify the document, but no live exchanges on the platform. Google Drive is linked to our Gmail accounts. It's going to be hard to compete with that."

"It's good, but we are all on Facebook and LinkedIn, so we use them to correspond. We use text messages, too. The platform gets used more or less.... There are a lot of online tool, Facebook, our cell phones.... A kind of LinkedIn was recently set up with the cohort, but can we post on that and it will be the same? ... We already use lots of tools...everything gets sent by texting or e-mail. That's just more natural."

Platform appeal: The participants also raised some platform characteristics that impeded its use. 
"Once you have faster means of communication, you don't want to go back. In my opinion, that impeded things. The aspect of discussions and interactions (time). The platform's user interface. I think it's ugly. I don't think it looks modern, it's rather out of fashion. It just doesn't have today's functionalities. It's basic. Other than what I use (links), there's nothing that I can't find elsewhere, no innovative functions (e.g., Google Drive)."

"Maybe the user interface, too...it's like it's left over from 2000 or 1990...it's much better than the University of Sherbrooke's portal, which is...dreadful. An old site that has never been updated cluttered with text and colors (choice of colors and questionable graphic lines) in the platform and portal. But the platform is interesting. There are icons (Moodle e-mail tiles, etc.) and you don't have to look for things. If you were to compare, I tend to use the collaborative platform instead of the University of Sherbrooke's portal."

"You don't really have the impression that it's up-to-date. It's more than the user interface. I'm not inclined to use it; I tend to use text messaging."

\section{Discussion and Contributions to Practice}

Our study highlights factors that could encourage or discourage participation in an collaborative platform. It sheds light on the dynamics of virtual collaboration in an academic context and can easily be adapted to organizational contexts. There has been little research that describes the nature of activities that help stimulate participation (Ref. [14]). Our study gives a clearer picture of the forces driving and impeding the introduction of these new virtual spaces.

If implementing collaborative tools and platforms facilitates collaboration in principle, they do not do so every time.

For practitioners in organizations that wish to implement virtual collaborative platforms our study stresses the importance to involve participants at the outset in order to clearly understand the need and how this need is actually satisfied. A thorough need's analysis would provide specific requirements and a sense of ownership on behalf of the participants. Our study recognizes the importance of the concept of perceived usefulness, which has a determining impact. As indicated in the TAM (Technology Acceptance Model) proposed in Ref. [8], a technology's perceived usefulness - that is, "the degree to which a person believes that using a particular system would enhance his or her job performance"-plays a role in inciting the person to use the technology and become involved. Involving the participants from the outset in identifying needs appears to enhance the perceived usefulness and, consequently, the intention to use the technology. Specifically, this study stressed the importance of involving participants in designing this type of collaborative space. It is also necessary to take into account how potential users assess the cost-effectiveness of investing in the proposed tool instead of the known alternatives at their disposal. The costs and benefits of using a system are assessed by measuring the advantages and disadvantages of alternative systems that users are familiar with. 
Our study also revealed that, while the social dimension positively impacted participation as a result of the in-person interventions, the impact diminished over time. These preliminary findings indicate that the virtual community studied - similarly to the findings in Ref. [3] — was not solely driven by outside forces and, at a certain point, member activity must come into play. Such activities allow members to build relations between themselves, create a climate of trust, and respond to their shared needs. Accordingly, the in-person sessions created a context conducive to the emergence of student participation, yet were not enough alone to maintain participant interest.

The following model (Figure 4) consists of the proposed conceptual framework revised to include the information yielded by our research.

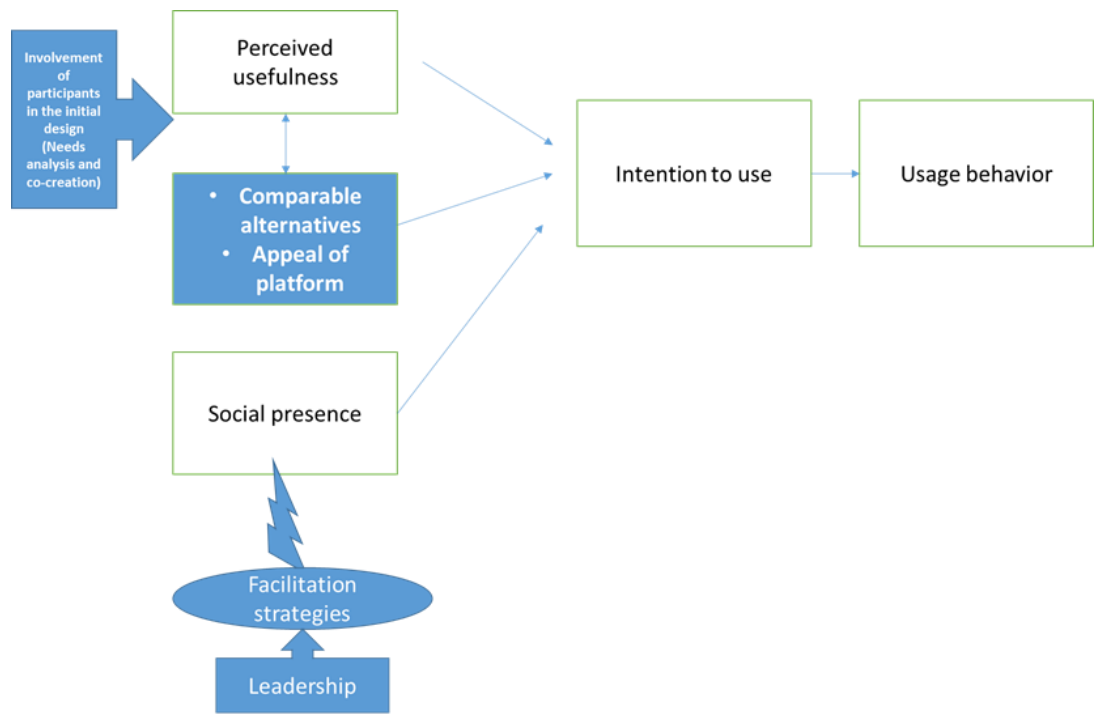

Fig. 4. Revised model of the determinants in participating in virtual communities (adapted from Ref. [8], Ref. [9], and Ref. [10])

For educators, this study points to the importance of implementing facilitation strategies when the tutor needs to act as a guide or serve as a scaffold between students and resources, and to provide stimulation and support. It also stresses the importance of involving students at the outset of the needs-definition phase.

\section{$5 \quad$ References}

[1] Hall, C. \& Cotsman, S. (2015). Learning as a Lever for Performance. Conference Board du Canada.

[2] McDermott, R. (1999). Why information technology inspired but cannot deliver knowledge management California Management Review; Summer 1999; 41, 4; ABI/INFORM Global (pp 103). https://doi.org/10.2307/41166012 
[3] Wenger, E., McDermott, R. \& Snyder, W. M. (2002). Cultivating Communities of Practice: a Guide to Managing Knowledge. Boston: Harvard Business School Press.

[4] Henri, F. (1992). Computer conferencing and content analysis. In A. R. Kaye (dir.), Collaborative Learning Through Computer Conferencing (pp 117-136). Heidelberg: Springer. https://doi.org/10.1007/978-3-642-77684-7 8

[5] Pozzi, S., Noss, R. \& Hoyles, C. (1998). Tools in practice, mathematics in use. Educational Studies in Mathematics, 36(2), 105-112. https://doi.org/10.1023/a:1003216218471

[6] Fulk, J., Schmitz, J. \& Steinfeld, C. (1990). A social influence model of technology use. In J. Fulk \& C. Steinfield (Eds.), Organization and Communication Technology: 117-141. Newbury, CA: Sage. https://doi.org/10.4135/9781483325385.n6

[7] Gupta, S. \& Kim, H. W. (2007). Developing the commitment to virtual community: The balanced effects of cognition and affect. Information Resources Management Journal (IRMJ), 20(1), 28-45. https://doi.org/10.4018/irmj.2007010103

[8] Davis, F. D. (1986). A technology acceptance model for empirically testing new end-user information systems: Theory and results (Doctoral dissertation, Massachusetts Institute of Technology).

[9] Schmitz, J. \& Fulk, J. (1991). Organizational colleagues, media richness, and electronic mail: A test of the social influence model of technology use. Communication research, 18(4), 487-523. https://doi.org/10.1177/009365091018004003

[10] Koh, J., Kim, Y. G., Butler, B. \& Bock, G. W. (2007). Encouraging participation in virtual communities. Communications of the ACM, 50(2), 68-73. https://doi.org/10.1145/12160 16.1216023

[11] Dubé, L., Bourhis, A. \& Jacob, R. (2005). The impact of structuring characteristics on the launching of virtual communities of practice. Journal of Organizational Change Management 18(2), 145-166. https://doi.org/10.1108/09534810510589570

[12] McDermott, R. (2001). Knowing in community: 10 critical success factors in building communities of practice [En ligne], Community Intelligence Labs. Repéré à http://www. co-i-l.com/coil/knowledgegarden/cop/knowing.shtml.

[13] Fontaine, M. (2001). Keeping communities of practice afloat. Knowledge Management Review, 4(9-10), 16-21.

[14] Yuan, J. \& Kim, C. (2014). Guidelines for facilitating the development of learning communities in online courses. Journal of Computer Assisted Learning, 30 (3), 220-232. https://doi.org/10.1111/jcal.12042

[15] Liu, X., Magjuka, R. J., Bonk, C. J. \& Lee, S. (2007). Does sense of community matter? Quarterly Review of Distance Education, 8, 9-24.

[16] Davis, F. D., Bagozzi, R. P., \& Warshaw, P. R. (1989). User acceptance of computer technology: a comparison of two theoretical models. Management science, 35(8), 982-1003. https://doi.org/10.1287/mnsc.35.8.982

[17] Purnomo, S. H. \& Lee, Y. H. (2013). E-learning adoption in the banking workplace in Indonesia: an empirical study. Information Development, 29(2), 138-153. https://doi.org/10. $1177 / 0266666912448258$

[18] Johnson, R. B. \& Onwuegbuzie, A. J. (2004). Mixed methods research: A research paradigm whose time has come. Educational researcher, 33(7), 14-26. https://doi.org/10.3102/ $\underline{0013189 \times 033007014}$

[19] Kim, A. (2000). Community Building on the Web. Berkeley: Peachpit Press.

[20] Sharp, J. (1997). Community of practice: A review of the literature. [En ligne]. Repéré à http://www.rcinet.com/-sharpkop-1it.ht.

[21] Karsenti, T. \& Savoie-Zajc, L. (2011). La recherche en éducation: étapes et approches (3e éd.). Saint-Laurent: Renouveau pédagogique. https://doi.org/10.2307/j.ctv69sv3w.8 


\section{Authors}

Joanne M. Roch, PhD, Full Professor, Université de Sherbrooke, Québec, Canada. Joanne.roch@usherbrooke.ca

Jean-François Roussel, PhD, Full Professor, Université de Sherbrooke, Québec, Canada. Jean-Francois.Roussel@USherbrooke.ca

Article submitted 2019-03-21. Resubmitted 2019-05-10. Final acceptance 2019-05-20. Final version published as submitted by the authors. 